\title{
Caregivers of Children with Incarcerated Parents
}

\author{
Ande Nesmith ${ }^{*}, 1$ and Ebony Ruhland ${ }^{2}$ \\ ${ }^{1}$ University of St. Thomas, Minnesota $55105 \cdot$ USA \\ ${ }^{2}$ Council on Crime and Justice, Minneapolis, MN 55415, USA
}

\begin{abstract}
With rising attention toward the plight of children with incarcerated parents, there has, as yet, been little focus placed on the adults who care for them, individuals who may have a profound impact on the children's relationships with their incarcerated parent. This study explores unique parenting challenges the caregivers faced, from their perspectives and presents their voices. Caregivers discussed the strain of serving as a gatekeeper between the child and imprisoned parent, coping with stigma and isolation, and negotiating a predominantly child-unfriendly visitation system. The findings suggest that caregivers need information about raising a child in this context, connections with others in similar situations, and a more child-friendly and transparent judicial and visitation process.
\end{abstract}

Keywords: Children of incarcerated parents, caregiving, impact of incarceration.

\section{INTRODUCTION}

There are an estimated 1.7 million minor children with a parent in federal or state prison in the U.S., representing a 79 percent increase between 1991 and 2008 [1]. With a burgeoning population of children with parents in prison, so too increases the number of caregivers who raise them in the context of separation and loss [2]. It is difficult to adequately support a child without supporting their caregivers. The impact of parental incarceration on children is intimately intertwined with that of the caregivers [3]. Caregivers must make critical decisions that can influence how the children experience their loss as well as the nature of their relationships with their incarcerated parent. A caregiver who is stressed and lacking support, or who has taken in additional children will likely be less equipped than others to support the child through the separation.

While the challenges caregivers face draw some parallels with other reasons that children are separated from a parent, such as divorce, there are some important distinctions. Contact between the child and the imprisoned parent, even when all parties are agreeable to it, is controlled by a third party institution (the prison) that establishes the terms of engagement: the schedule, visiting space, duration, and degree of physical contact. Caregivers of children with incarcerated parents may have to help children cope with the trauma of witnessing their parent's arrest. Finally, there is a social stigma of having an association with an incarcerated person which may inhibit the receipt of needed social support.

Not much is known about how these differences play out among caregivers of children with incarcerated parents. While there is more information available in recent years as to the demographics of caregivers, very little is known about

*Address correspondence to this author at the School of Social Work, SCB 201, University of St. Thomas, 2115 Summit Ave., St. Paul, MN 55105, USA; Tel: 651-962-5805; Fax: 651-962-5819;

E-mail: nesm3326@stthomas.edu the personal experiences of the caregivers or how the challenges unique to their situations unfold $[3,4]$.

\section{LITERATURE REVIEW}

Much of what we know about caregivers of children with incarcerated parents must be derived from studies aimed at the children. From these, we are able to piece together some caregiver characteristics as well as some of the adversities they may confront.

\section{Scope of the Problem}

The caregivers of children with a parent in prison will likely remain in their caregiving role for a significant portion of the minor's childhood. In 2005, among 636,300 parents in state prisons across the nation, more than half had been in prison one to five years and another 25 percent had been in prison five or more years [1]. Among this same population, 38 percent had an additional one to five years before anticipated release; another 20 percent were not expected to be released for five or more years, if at all. Many caregivers will be responsible for the children as they transition into adulthood - more than one-third of the children will reach age 18 before their parent is released [1]. Moreover, these statistics do not touch on the issue of multiple prison terms over the course of one's childhood. Dramatic developmental changes can occur in a span of five or more years of childhood, exacerbating the caregiver's efforts to help children stay meaningfully connected to their incarcerated parent during their absence.

\section{Who are the Caregivers?}

The Annie E. Casey Foundation conducted an extensive review of the research literature on children of incarcerated parents, as well as drawing information from the Survey of Inmates in State and Federal Correctional Facilities [4]. They reported that $80 \%$ of the time children live with their other parent when one parent is incarcerated. When the incarcerated parent is the father, in $90 \%$ of the cases, the children live with their mothers. However, when the mother 
is incarcerated, the children are more likely to live with a grandparent (45-53\%) than their father (28-31\%). About $10 \%$ of incarcerated mothers report that their children reside in foster care. However, foster children with incarcerated parents are more likely to already reside in a foster home when incarceration occurs rather than enter foster care because of parental incarceration [5]. In interviews with mentors who have contact with the children and their caregivers, the caregivers were described as hardworking and dedicated to the children but struggling financially, and in the case of grandparents, struggling physically as well [6]. Despite the strain, an advantage of relative caregivers is the familiarity with the child. Mothers and grandmothers often assumed much of the caregiving role prior to incarceration, potentially moderating the impact of the parent's incarceration on the child, as compared with those who were placed with non-relatives [7].

\section{Caregiving Challenges}

There is no shortage of adversities future caregivers may face long before parental incarceration, particularly among relative caregivers. In many cases, the family has a host of pre-existing problems, such as poverty, family discord, substance abuse, or other criminal behavior that may have contributed to or culminated in incarceration [6-10]. Incarcerated parents are more likely than other parents to have histories of trauma or limited coping skills, and because prison can diminish these skills, it can enhance estrangement between the child and parent [11].

A parent's history of encounters with the justice system prior to imprisonment, such as arrests, may have profound effects on the children as well. When arrests occur in the presence of children, the experience can be traumatizing and the impact enduring [12]. Police officers are not always wellequipped to help children at the scene of an arrest. This is not only a concern during arrests. Children and caregiver needs are not generally considered in any part of the judicial process, yet their lives are often significantly affected by those decisions.

Once the parent has been sentenced to prison time, two key elements play a notable role in the possibility of sustaining contact and communication between the child and parent: the location of the prison relative to the child's home and the visitation environment. The distance between a child's home and the prison can significantly hinder the caregiver's ability to bring the child to visits. Sixty-two percent of state and 84 percent of federal imprisoned parents are held more than 100 miles from their most recent residence, often in rural settings while the prison population stems predominately from urban locations [13]. Hairston, Rollin \& Jo [14] found that among prisoners placed within 50 miles of their homes, 46 percent had no visits from their children, whereas among those placed 101 to 500 miles away, 70 percent had no visits. The barriers of such distances may prove insurmountable if the caregiver has an unreliable vehicle, inflexible work hours, or insufficient funds to cover the costs of travel.

The larger issue with visits may not be getting to the prisons but the visiting environment itself, which can be unsettling to both caregivers and children. While a decision to keep children from visiting may sometimes be tied to caregiver feelings about the incarcerated parent, it may also be a well-intentioned effort to protect children from the prison setting. Fathers, who are more often the incarcerated parent and less often the primary caregiver pre-incarceration, may interpret this as an effort to thwart their relationships with their children [15]. However, children themselves have reported that the visiting experience can be disturbing. Interviews with children who visited their parents in prison revealed that children sustained memories that included images of a frightening place with insensitive guards, barred windows, and unforgiving rules [16]. The visiting spaces, particularly in men's prisons, are often reported to be sterile or uncomfortable, with limited privacy and child-unfriendly visitation rules $[17,18]$.

\section{Stigma}

Children of incarcerated parents sometimes find that their peers shun them or violate their privacy because they have a parent in prison $[16,19]$. Caregivers too may suffer from similar reactions. Although the caregivers themselves are not in prison, they can suffer from associative stigma. Associative stigma occurs when a person is ostracized or fears stigma because of his or her close link to someone else who is a member of a stigmatized group [20]. Examples of people who have experienced associative stigma include parents of children with disabilities, individuals related to someone who is incarcerated, caregivers of persons with AIDS, and individuals related to someone with a mental illness [20-22]. Associative stigma is a type of concealed stigma in which one cannot tell that the individual is part of or linked to a stigmatized group simply by looking at them $[20,21]$. Because the stigmatizing feature can be hidden, it also sometimes means that the individual experiencing associative stigma may hear degrading or otherwise hurtful remarks made in their presence by others who are not aware of their connection. Consequently, caregivers may fear they will be blamed for the incarceration, or for making a poor choice as a caregiver, especially if the caregiver has a current or prior dating or marital relationship with the imprisoned parent. This is a known as anticipated stigma. Anticipated stigma has been found to lead to depression, strained relationships or constricted social networks, and low selfesteem [23-25].

\section{Summary}

With virtually no information in the research literature on the caregiver experience, it is unclear what actions should be taken to support them. The vast majority of the information we do have about caregivers comes from indirect sources and tends to be demographic data. As more individuals find themselves responsible for raising a child whose parent is incarcerated, it is increasingly important to understand the difficulties that are unique to their situation. Such information will better inform communities, the justice system, and service providers on how to best support them.

\section{THE PRESENT STUDY}

The present study introduces the voices of the caregivers, their perspectives on raising children with a parent in prison and what they perceive as their most significant challenges. The results are drawn from a larger study that explored the impact of parental incarceration on children and their 
caregivers via in-person qualitative interviews. In the larger study, the focus was on the children [16]. Here, we turn to their caregivers to learn their subjective experiences around parenting in this context. We sought to answer the following questions:

- What are the unique aspects of caring for or raising a child in this context?

- What are the caregivers' principal concerns in regard to parenting?

- In what ways are the caregivers themselves affected by raising a child who has an incarcerated parent?

- Where have the caregivers found support, if any?

We present the themes that surfaced and caregiver reflections on caring for a child with a parent in prison. In this paper we turn to the caregivers' own words to exemplify each theme.

\section{METHODS}

The study employed qualitative methods to gather and synthesize information collected from twenty-one caregivers in three interviews conducted over twelve months. The interviews were intended to reveal experiences that better elucidate the impact of parental incarceration on caregivers.

\section{Sampling}

The study sample was drawn from the Minneapolis/St. Paul metro area and included families with a parent currently in prison and at least one child between the ages of eight and seventeen who could be interviewed for the child portion of the project. Because we sought to interview children as well as caregivers, it was a requirement that the child was aware of their parent's incarceration. The original study aimed to gain children's perspectives on their parent's incarceration and the impact it had on their lives. Therefore the sampling process was centered on child characteristics. We selected a minimum age of eight years because children this age and older are more likely to have the ability to assess and articulate their feelings and insights on their situation. While the impact of parental incarceration on younger children is equally as important, it would require a different approach to gathering information, such as observation or indirectly from the perspective of their parents. The findings presented here are drawn from the caregivers of these children.

Locating families with a parent in prison proved to be a formidable task. There was not a resource or database from which we could identify a random sample or establish a clear sampling frame. There was no location where such families gathered, and, possibly due to anticipated stigma, there was reason to keep the incarceration concealed. Furthermore, there was no formal system of tracking the families. The local public schools did not document when a student had a parent in prison, nor did most other organizations that had contact with the families, such as community centers or churches. The prisons, although they did collect data on how many prisoners had minor children, did not make efforts to verify the data nor did they gather any contact information on families. Prisoners who did not wish to reveal their families, or families who did not have contact with the prisoners would not be found this way.
Therefore, multiple approaches were used to reach potential participants. To improve the response rate, we targeted neighborhoods with the highest concentrations of adults currently in prison and returning from prison. We located the neighborhoods using Department of Corrections maps of incarceration and reentry. We targeted these neighborhoods for recruitment. We enlisted the help of the community organizations that caregivers and children were most likely to frequent. This included mentoring programs, neighborhood child and youth programs, and other small organizations aimed at supporting caregivers of children with incarcerated parents. Invitations to participate were broadly posted at program gathering locations. The agency staff also inserted study invitations in their routine mailings to families. To reach families who were not associated with children's programs or support services, we also advertised in locations reaching a broader audience, such as grocery stores, laundromats, public libraries, and parks.

Ideally we would draw a sample that specifically varied on important demographics such as the child's and caregiver's gender, but given the difficulty of locating participants, we were not able to pre-select on these factors. The sampling frame can best be described by the targeted neighborhoods and the state prison statistics. The neighborhoods were disproportionately economically disadvantaged and comprised greater concentrations of families of color, particularly African Americans, than seen in the general population. The prisons have similar disproportionate racial and ethnic distributions. Ninety-four percent of the state's prison population were males. Thirtyseven percent were African American, 7 percent Latino, 7 percent Native American, and 46 percent Caucasian $[16,26]$. According to inmate reports, there were approximately 1,700 parents who have minor children (including step-children) in Minnesota [26].

\section{Obtained Sample}

Twenty-one caregivers with a total of 34 children responded and enrolled in the study. All caregivers were female relatives of the child, including mothers, aunts, and grandmothers. The family structures were often fluid, making it difficult to describe the families in any one way. Adult relatives moved in and out, sometimes with their own children. Older adult children also moved in and out throughout the course of the study. At the time of the interviews, all the caregivers were single-parenting one to five children as young as six months and as old as sixteen years. Sixty-two percent of the caregivers identified as African American, 19 percent were Native American, and 19 percent were Caucasian.

\section{The Children}

Of the 34 children, 21 were boys and 13 girls, ranging in age from 8 to 17 years. We asked the children to self-identify their race or ethnicity, rather than assigning it to them. The children all identified themselves in line with the caregiver's ethnicity. However, one child who identified as African American also had a Caucasian parent and one child who identified as Native American was also Hispanic.

\section{The Incarcerated Parents}

The incarcerated parents included all of the children's fathers. Two children had incarcerated mothers as well as an 
incarcerated father. As noted earlier, there was no data collected directly pertaining to the imprisoned parents. We asked the caregivers to provide their knowledge about the convicting offense, duration of current prison sentence to date, and history of imprisonment. Some were vague about the facts or not confident of their accuracy. Caregivers did not always distinguish between charges and convictions, or when there were multiple offenses, what combination led to conviction. Therefore, while we report below an overview of the parent incarceration characteristics, they should be viewed cautiously and only as perceptions rather than facts.

According to the caregivers, among the 23 incarcerated parents (all the fathers and two mothers), the convictions included drug charges $(26 \%)$, burglary or robbery $(13 \%)$, murder, homicide, or attempted murder $(13 \%)$, and probation violations $(9 \%)$. The remaining were either unknown to the caregiver or a mix of other charges including sex offenses, driving while intoxicated, and assault. There were some cases in which the most recent charge was a probation violation. Because, in these cases, the incarcerated parents had a long history of arrests, the caregivers were unsure what the original offense was. When asked how many times the parent had been imprisoned, the caregivers reported that 12 $(52 \%)$ parents had been in prison either more than twice previously or were "in and out." Two were serving their first sentence, and two had been in prison once previously. Caregivers were unsure about the remaining seven parents. The caregivers were more confident about how long the parent had served their current sentence. According to the caregivers, the parents had been in prison an average of 4.3 years with a range of 1 to 8 years. The median age of the targeted children at the time of arrest leading to the current incarceration was 5 years old.

\section{Data Collection and Analysis}

The data collection methods were designed to gather rich, in-depth information from the participants' personal experiences. An advisory board contributed to the interview development. The board was comprised of caregivers, exoffender parents, child mentors, community program directors, a judge, and a family psychologist, all of whom had some experience with families with an incarcerated parent.

\section{Interviewers and Interview Settings}

There were eight interviewers; five were female and three male, three African American and five Caucasian. The interviewers were similar in age to most of the caregivers, ranging from their mid- 20's to early 30 's. The interviewers were trained in qualitative interviewing techniques and in conducting the informed consent process.

The caregivers selected the setting for the interviews, most often in their own homes, though some took place in public libraries, local parks, and the researchers' offices. Prior to commencing with the interviews, the caregivers provided written informed consent for participation in the study and for audio-recording the interviews. The interviewers revisited the consent forms with the participants at each consecutive interview. Caregivers were given gift cards to a local department store for participating in the study. Each interview lasted approximately ninety minutes.

\section{Interview Development \& Data Analysis}

The interview development is intertwined with the data analysis process. The data analysis employed qualitative analytic principles, drawing on template analysis methods. The interviews were designed to capture the fluid roles and meanings around the topic of parental incarceration.

Three rounds of in-person interviews were conducted with the same individuals, using the same interviewers. The interviews were intentionally loosely structured to allow the interviewer to probe more deeply when caregivers introduced new topics or experiences that might shed light on how incarceration impacted them and their parenting. Therefore, we developed interview guides that ensured that the same key topics were covered in every interview but permitted flexibility to explore unique or emerging stories.

The first interview began with broad exploratory questions that addressed issues raised in the research literature as well as by the advisory board. The interview topics included: 1) the caregiver relationship to the child and the child's incarcerated parent, 2) how the child learned of the parent's incarceration, 3) the perceived influence of incarceration on the caregivers' lives and the children's lives, 4) how the incarceration affected their parenting decisions, and 4 ) in what ways they struggled or found support.

We employed an iterative approach to the interview questions, assessing first for broad themes and then under those, organizing the emerging concepts into smaller themes after each of three waves. Based on the findings after each wave, we refined the questions for the next interview. With this method we were able to gather more focused details with each new interview that pertained to the key factors most relevant to the caregivers' parenting experience.

Each team member read all the interview transcripts independently. As they found themes in the responses, they gave them a brief code name by which they identified additional examples in the transcripts. This was followed by a group process to establish agreement of thematic content by the research team. The research team met to present and discuss their individual findings. Through this process, we focused on our overlapping or similar themes and reached agreement on which were examples of emerging themes that would improve understanding of the topic. In template analysis, the "template" is essentially a list of indicators selected and given a name or code by the researcher [27]. For each theme the team established a set of indicators. Using these indicators, the team returned to the transcripts to locate the full range of examples within each theme, including any outliers. The themes were shared with the advisory group which offered insight into contextual factors and assisted in identifying which of the themes had the most potential to expand knowledge in the field.

Using the findings from the previous interview wave, the subsequent interview questions were constructed to explore more deeply and consistently the themes that surfaced in the first interview. For example, while the first interview did not ask specifically about the parent's arrest, this was raised several times when caregivers were asked how the child learned about the incarceration. When we learned that some children witnessed the arrest and that the experience was largely traumatizing, we asked all participants in the second 
interview to share what they knew about or personally experienced in regard to the arrest. Witnessing the arrest became a theme under the broader topic of the unique aspects of raising a child with an incarcerated parent.

We continued adding new questions to subsequent rounds of interviews to confirm, reject, or adjust possible themes as we gathered more consistent and specific information from all the participants. By the third interview, we reached a point of saturation. That is, no new themes emerged and we had explored the previously identified themes with all participants.

\section{Limitations}

The study participants represent a limited group. They were all women, self-selected, and mostly resided in economically deprived and high-crime neighborhoods in a single metropolitan region. The views expressed here are the personal and unique opinions and stories of the participants and do not reflect the full spectrum of caregiver experiences for this population. Rather, they offer insight into the depth and nuances of individual experiences among caregivers.

The focus of this work centered around the caregivers and their experiences rather than on the incarcerated parent and their arrest or criminal history. The imprisoned parents were not part of the study; any information about them should be viewed as a reflection of the caregiver's perspective. While we asked the caregivers to describe their understanding of the incarcerated parents' convicting offense(s), their responses may not be accurate.

\section{THEMES}

The following sections present the findings, organized by the themes that emerged from the interviews. We present the themes and excerpts from the stories caregivers shared as they responded to the interview questions. We first address issues the caregivers were confronted with that were unique to raising a child with an incarcerated parent. We then explore the ways in which caregivers were directly affected by the experience. Finally, we present their thoughts about how they coped and found support.

\section{Unique Aspects of Raising a Child of an Incarcerated Parent}

Three themes arose that spoke to the unique challenges of raising a child with an incarcerated parent. The first is the acute stress caused by the arrest experience that the caregiver and/or the child may have witnessed directly. Here, the caregivers found themselves in situations for which they had little knowledge, history, or resources to guide them in their parenting decisions. The next theme, the necessity and complications of gate-keeping, is demonstrated with stories about negotiating the interactions and relationship between the child and incarcerated parent in the context of third party (the correctional institution) rules and constraints. The third theme centers around how caregivers assessed the risks, benefits, and obstacles to prison visitation.

\section{Witnessing Arrest}

When we asked the caregivers how the children learned about their parent's incarceration, stories regarding the arrests emerged. In the research literature, there is some discussion about the impact of observing arrests on children. What is not discussed is that the caregivers too can be traumatized by witnessing an arrest. Not all the children nor all the caregivers were present for the arrest, but when they were, the experiences were usually disturbing to the observers. We heard examples of associative stigma in their stories about how they were regarded by the police during arrests.

I feel like I was a criminal and I didn't do anything. Even if I was there with my son...you feel like you did something wrong, and you didn't do anything wrong... I didn't feel like I was treated like a person, more like a criminal.

When children were present at the arrest, caregivers were anxious about the impact on the children and their lack of control over how the child was exposed to the arrest. One caregiver revealed how the arrest not only left them without the father but also left them stranded at the side of the road. Her story took place as she and the child's father were driving their daughter home from school,

I got pulled over and then there was a warrant. So they just took him out of the car and they towed our car and we had to get out and walk...put us out, towed the car, gave me a card and said this was where you can get your car back. It was like real simple, just run to the school and come right back, so I didn't have any ID. I didn't have anything on me, so that's why they said we can't let you take the car... [the police officer] said they were supposed to take me down to book me, to see if I'm the person that I says I am. He said he felt like he was doing me a favor by not taking me to jail in front of my daughter, so I mean I couldn't argue with that. I didn't want to go to jail in front of my daughter, you know. So we walked home.

Some families witnessed the arrest in their own homes. This was usually a disorienting and stressful event as they were caught off guard, sometimes in the middle of the night. This caregiver also was viewed by the police as someone who might engage in illegal behavior.

They come banging on my door, then I open the door and they ask for him...I was real curious why. They didn't talk to me about it, they just wanted to know where he was...I said 'ok he took off through the back room.' That is when they told me I could go to jail for hiding him. I said I am not hiding him, I just wanted to know what he was doing. He didn't tell me and you guys didn't tell me...I am still cooperating... I wanted to know.

Sometimes the police encounter was disorienting because it came in the middle of the night. A caregiver described in detail a frightening raid when she was alone with her teenage daughter,

They came to the house in the middle of the night. They came here and it was actually 
while we were asleep and they showed up here at 2:30 in the morning with a warrant. They flashed the lights and came through the back door. And my kid was here. She was, we were both shocked because they had their guns drawn and all kinds of stuff. There were six of them. They had people around the house... I never come down and just open the door...I'm not going to come down and open my door and look out there and have somebody shoot me. You never know. So I went to the window and was like 'who is it?' and they were like 'it's the police, open up...'

The caregiver further explained how she believed that the situation could have been handled differently,

I think maybe they could be doing it differently and not at 2:30 in the morning, you know, be sensitive to the other family members. I mean because they could have just as well gotten him walking down the sidewalk during the day as they could have done at 2:30 in the morning. Then all he could say to me at the end was 'well we just want to thank you for your honesty and we appreciate you cooperating with us.' That was the best that you can do? You run through my house with guns and me and my daughter are here and that is the best that you can do? The weirdest thing is that any other time there would have been a house full of teenagers in here, spending the night on the floor watching TV, you know, and maybe at 2:30 in the morning, they would have gone to the window first or listened at the door. A house full of kids and things could have gotten really chaotic, somebody could have run up the stairs and they could have shot up the place.

This caregiver was not only worried about the impact of her daughter witnessing her father's arrest, but was also shaken by a close call with a tragedy had it been a typical night with several teens spending the night.

When the child witnesses the arrest, the caregiver does not have the opportunity to break the news of incarceration gently or in a developmentally appropriate manner to the child. Rather, they must explain the incidents that unfolded before the child's eyes. That experience may be the child's lasting memory during the prolonged separation from the parent.

\section{Gate-Keeping}

Caregivers had little option but to serve as the gatekeeper of the child's relationship with their incarcerated parent. It was incumbent upon the caregiver to orchestrate the parentchild relationship, beginning with how and when the child was informed of the parent's incarceration, to deciding whether or not the child had contact with the parent. The caregivers were in the position of influencing the nature and quality of those contacts. Nearly all the children in this study expressed a desire for a connection and regular communication with their incarcerated parent [16]. Because the prisoners did not have free access to visit with or even initiate phone calls to their children, such decisions were left in the hands of the caregivers. For the caregiver's part, choosing to encourage and support an active relationship between the child and incarcerated parent required intentional effort. Caregivers remarked that a decision to remain neutral by inaction was tantamount to denying access, because without their coordinating efforts, no communication could occur. It was the caregivers who had to accept and fund collect calls from the incarcerated parent and caregivers who had to coordinate visits. Similarly with communication via letters, most of the children who wanted to write needed a caregiver to help them express their ideas and get the letter mailed to the correct address.

When a parent becomes incarcerated, unless the child witnessed the arrest, the caregiver is also left with the task of informing the child of the incarceration, or choosing not to, and conjuring another explanation. We learned about the temptation to lie to the child during the recruitment process for this study. Some agencies that work with these families reported that many caregivers had expressed an interest in participating in the study but had not told the children of the incarceration, including some children enrolled in a program specifically for mentoring children of incarcerated parents. The caregivers, according to the agencies, told the children that their parent was on an extended vacation, had work in another city, or avoided any mention of the parent. Some caregivers in the present study elected to delay telling the children until they were older and more mature. One caregiver shared how she handled this with her son who was two years old at the time of sentencing.

[I didn't tell him] because at that time he was too little. I just told him daddy's on vacation because at that age, children don't really understand. He was seven [when he learned about the incarceration] because he was going to school and they had a father and son activity and he was like 'mom is dad going to be here for it?' and I was like, 'no, there is something I need to tell you.' So, I took him to the library, got on the internet and showed him and he was just like, 'how long he been in there?' He been in there for awhile. He asking when he's going to get out. I said I don't know. It had the address on there where you can write, so he wrote him.

Much like divorced parents, the primary care provider can have a great deal of influence over the child's relationship with the non-custodial parent. However, this group of families differs from divorce in that there is a stigmatizing event requiring explanation. Furthermore, a third party plays a significant role in the distance and communication restrictions. Even when contact is desired by all family members, caregivers reported it is difficult at best because of physical distance, visitation and phone regulations, and the discomfort of the visiting space and rules.

Some caregivers struggled with the conundrum of both wanting the children to have a relationship with their father, yet not trusting him with their children. When one of the caregivers shared that the father had spent time with the child between recurring prison terms, we asked her to tell us 
about the parent-child interactions during those interim breaks. The caregiver explained that she did not trust the father's judgment and the risks her child might be exposed to with the father.

Well, I would never let him take him from my house because he sold drugs and I was nervous that my son would be in the car and something would happen, because [the father] had gotten shot before.

This caregiver felt she had to confine visits to their home for the safety of the child yet still permitted visits because she believed it was important for the child to see his father.

Without the aid of caregiver interventions to explain and interpret behavior to both the child and incarcerated parent, the depth and quality of contacts risked decline. This was especially true when imprisonment lasted many years and the incarcerated parent was absent during their children's significant developmental milestones. For example, caregivers told stories about older children feeling embarrassed or frustrated when an incarcerated parent asked them about a childish cartoon or about an activity for younger children that they had outgrown. Caregivers felt they were left with the responsibility of helping the incarcerated parent understand the changes in the child over time and to suggest new ways of interacting with the maturing child.

One caregiver reflected on the awkward telephone conversations her son had with his father and her wish that the father would talk about more meaningful topics.

He doesn't understand how to talk to him. When he did talk to him it was about stupid stuff. Instead of saying, you know, "do you know what happened?" And "I'm going to be here for a long time, but I still love you," or something like that, that [the child] wants to hear. Instead [he is] just saying "what cartoon are you watching?" or something like that. That would make a difference and that would help, because I would feel better about him communicating with him.

Another caregiver described her disappointment at her unsuccessful attempt to reunite the child and father upon one of his releases from prison. She saw that the father did not recognize that the child wanted more than his physical presence, but also his attention. The father became angry when his daughter did not immediately warm up to him.

Her recent birthday I had invited him... and he was talking about wanting to see her. Okay, I will give you a chance. He was late to the birthday party, and was on the phone with a female [for much of the party].

In reaction to seeing her father arrive at the party distracted with his phone call, the girl hid in her bedroom. The caregiver described the resulting events.

... he told her "if you don't come out of this room and talk to your dad, I'll leave." She took his phone, threw it at the wall and she told him that she hated him and she was crying, and he was saying to me, "how can you let my daughter talk to me like that?" and I just told him you know what? That's how she feels, you know, she hears your phone call and you tell her if you don't come out of this room and spend time with your dad, you're leaving... As he was going out, [the child] ran behind him and she was like "Dad, don't go! Dad, don't go!" and he just looked at her and started cussing and walked off. So I immediately called him on his phone... and I just told him, I said, "all this that you was hollering about your daughter then you had the opportunity to spend time with your daughter and this is how you treat her?" So after that I haven't heard from him.

This caregiver understood the child's decision to hide was a reaction to feeling hurt that her father was ignoring her. The father, for his part, had possibly anticipated a warm unconditional reception, much as he had received the last time he saw her as a toddler. Both the father and the daughter parted with hurt feelings while the caregiver described feeling disappointed, angry, and ultimately responsible for the failed homecoming.

Several caregivers discussed how they coped with believing that the father was not in a good position to be an active parent or role model to the child while simultaneously recognizing the child's powerful desire to have that relationship. A caregiver shared that although she knew contact would likely result in her son getting hurt, she felt she had to give him the option.

No, I didn't want to take him [to visits] because I want to just protect my son. I felt guilty then after awhile like I didn't want to let him not have contact because of my feelings. I wanted him to be able to choose. So then I let him choose, my son choose. And my son chose to talk to him, but then he got hurt in the end anyway.

Another caregiver expressed frustration with the father's disinterest in maintaining a relationship with his children.

I think in some kind of way, every kid should know their father but then I think it's best that right now his dad don't come around until he gets his life together. The last time I saw him it was like in court...I don't never understand why you have kids and you don't want to take responsibility for them. I don't understand that. Because every day I have to wake up and tell my kids why their father is not in their life, you know? But they've talked about him...my daughter, every time she does or used to see him or talk to him, she starts crying, so I'm not going to push her or, you know what I'm saying, force her to have a relationship with him. But I don't never talk bad about their father. Never.

It was not uncommon for children to develop fantasies about their incarcerated parent. When this occurred, the 
caregivers usually tried to gently inform their children of the truth but also recognized their need for the fantasies.

[He] has this imagination that's like, okay, well my dad, I'm going to go see my dad and he's going to do this for me. He's going to do that for me. Me as a mom, I don't want to try to kill his - you know what I'm saying - his dreams because that's how he feels....he feels that one day he will be in his dad's life and his dad is going to do this and his dad's going to do that, you know, and I don't want to be like...well you know your dad ain't going to be...You know, I don't want to be like that to him because if I do that it's going to make me kill his whole dream.

Underlying most of these shared caregiver experiences was the absence of information, social support, or personal experience to guide them in navigating parenting responsibilities and decisions in the context of parental imprisonment. On the whole, the caregivers relied on their best judgment, based on their own feelings and understanding of the needs of the child before them, and hoped they would not regret their decisions.

\section{Negotiating the Prison Visiting System}

Caregiver efforts to provide in-person contact between the child and incarcerated parent were met with numerous obstacles for the families, including a lack of transportation to the prisons, child-unfriendly visitation rules, and childunfriendly visiting atmosphere. About a quarter of the families had visited the incarcerated parent at least once; fewer visited on a regular basis. For those who did not visit or who visited infrequently, the most-cited barrier was the absence of a reliable car. For others their job was a barrier because they could not get the needed time off. Sometimes the issue was the expense of the visit, which required an overnight stay for many families in a hotel due to distance, in addition to transportation costs. For children with parents sent out of state, visiting was impossible. In some cases the caregiver opted to forgo visits without ever attempting one. This was usually because they believed prison was not a good place for children nor a context in which they wanted the children to see their parent. One caregiver who made visits on her own wanted to bring her child and explored that idea with the staff at the prison. The prison case worker discouraged her from bringing the child.

They didn't be degrading or anything, but I called a couple times to talk with his case worker about whether or not I should bring [the child] to visit, and he was pretty much cut and dry. He was like, 'no. I wouldn't bring my kid here.' Which I appreciated his opinion, but he was not all pro-prisoner rights. He was like, 'keep your kid away.'

Another caregiver brought the child to visits as a baby so that the father could see him but once the child became old enough to recognize that his father was in prison, she discontinued visits.

When he was like what, two weeks, two months, and six months, I used to take my son to go see his dad in prison until I just got tired of doing that. You know, I didn't want to have my son keep seeing his dad behind bars.

For those who brought the children to visits, the experiences were strained or stressful, making future visits less appealing. The prison visitation rules were the primary complaint among the caregivers who attempted visits. Caregivers expressed exasperation with the prison visiting rules that, in their opinion, were unaccommodating to children and families, and at times irrational. The caregivers complained that the children were not permitted to bring toys or books and none were supplied by the prison. Furthermore, they were not allowed to move about and were not permitted to use the restroom during two-hour visits. We confirmed that these are indeed visiting rules [28]. A caregiver who put forth a great deal of effort to maintain regular contact between the children and their father revealed her frustration with the inflexible rules.

We go to see him at least every two weeks. We were seeing him once a week.

That's before he got in the hole [segregation], and got no contact visits. We don't like to go see him there... They only allow two people at the window, and I'm like 'well, he asked to see the kids' and they're like 'well, no more than two people.' And I'm like, 'well, what about his baby? Can his baby sit on my lap?' And they're like 'no.' So I said, 'basically, you're just telling me that I have to make two trips out here a week?' and they're like 'yeah.'

There was not an adequate alternative for this caregiver. She could not leave one of the young children in the waiting room alone, yet to leave one at home meant both paying for child care and denying one child time with their father each visit.

\section{The Impact of Parental Incarceration on Caregivers}

We asked the caregivers about the hardships they confronted as well as their sources of support. One of the first things mentioned was their fears about, and real-life experiences of, being judged for their connection to a prison inmate. Many of the caregivers struggled financially prior to the incarceration, but for several, the loss of the parent's financial support created additional strains. Their perceived support was limited, largely coming from immediate family members or not at all.

\section{Facing Associative Stigma}

There is much discussion in the research literature about the impact of social stigma on the children, but little reflection on how the same issues impact the caregivers and their parenting [26-28]. Many caregivers discussed the stigma they experienced from others as a direct result of the parental incarceration. The sense of stigma was particularly powerful when the caregiver's connection to the incarcerated parent was a current or past romantic relationship or when the parent's criminal behavior brought public attention. Some described friends or family members who questioned the wisdom behind their choice for a romantic partner. Other caregivers felt they were judged based on the incarcerated parent's actions. 
Lots of people think that when you have somebody that's in jail, whether it be husband, or boyfriend, or brother, or whatever, that you're bad too. But it's not true, you know? Just because that person did that, doesn't mean that you would. I've like, met people, and then it comes out after maybe a two-month relationship and then they think that you accepted or condoned it and that's not true. And it doesn't mean that the kid is bad too. It just means that it happened. A lot of people assume.

A caregiver who had been married to the incarcerated parent discussed the stresses and hassles she endured because of her ties to the incarcerated parent.

Having to deal with people like parole officers calling me. Having to deal with police breaking in, coming in and breaking my door down looking for you because you was, whatever they call that, harboring a fugitive, you know, and people used to say well if [the incarcerated parent] messes up, the first house they going to come to is yours because you're married to him...I didn't want that. I was happy once the divorce papers came and I was a free person.

Most of the caregivers who had at some time been romantically involved, however, were never married to the incarcerated parent.

\section{Financial Strain}

Most of the caregivers struggled financially. For some, the incarceration led to the loss of significant income. Some had to move out of their homes and into smaller residences or move in with family members after the incarceration.

I had a really good job and stuff but I had to go to court for [the incarcerated parent]. So I was working two jobs, a full-time job and a parttime job and then when I lost my full-time job, my part-time job was just not enough to make it, so I ended up getting unemployment. So now I'm not working. So we're just living off my unemployment right now until I can find a good job... The lights have been out and the gas has been turned off.

Another caregiver also described significant financial changes.

The financial situation changed a lot. Just because when he was out here, he would pay everything for me, all the bills, and for my car and everything, and so now I have to do it all myself. And so now we're like extra, extra, extra broke.

One caregiver worried about having no food for her child and friends. In addition to her concern about meeting basic needs, she was aware that it could be embarrassing to her daughter.

You know like when [the child's] friends come over, I feel so bad sometimes so I try to do a little extra special stuff for her because like I hate when her friends come over here and there's no food. No cereal, no milk.

Some were poor both before and after the incarceration, but spoke of missing other contributions of the incarcerated parent. One caregiver missed the organizational skills that the incarcerated parent provided for the family budgeting,

I have never had been a budgeter. Yeah it's funny because [the father], I loved that about him. [The father] is the kind of person where when he was working, I would have to give the money to him and then he would budget. He would put the money on the bills...I really had to adapt to those kind of things, like, and not be such a frivolous spender. You know, the kids would need panties and bras and so it would be like, oh you know, I'm not even going to pay the phone bill. So when the phone would get cut off it would be such a shock. It would be like, oh I better take all this stuff back, I got to pay the phone bill because the phone is cut off. So I think what I really had to learn was how to budget.

There were outliers on this theme as well. Two caregivers reported that they fared better financially after the incarcerated because the parent had been draining their accounts and selling their belongings to support their drug habit. The incarceration brought them more financial stability as well as a more peaceful home environment.

\section{Sources of Caregiver Support}

In the pursuit to understand where and how caregivers found support, we learned that on the whole, the caregivers in this study were lacking in both formal and informal support. Although two caregivers found external means of support, more often the caregivers expressed frustration with their failure to find support among friends or support groups. Most of their support came from internal sources: religious faith and a drive to push on for the sake of the children.

We asked what got them through the hard times as caregivers of a child with a parent in prison. Nearly all stated that it was the children who got them through the difficult times and who motivated them to push forward when they felt despair.

I look at my kids, especially my baby, because I was carrying him when I [was] going through everything. So long as I look at him and he's just happy, I get the strength to do what I have to do to take care of him.

Another caregiver reflected a similar sentiment,

My children, I think if I didn't have my children, I don't know where I'd be today. When I look at my children, I know something needs to be done. And they pull me forward and say this is what needs to be done...my children make me a stronger woman .

The large majority of the caregivers also remarked on their belief in God or their spirituality as a source of strength and support. They did not speak of church, but rather of their 
faith that helped them surpass hurdles and allowed them to be present and supportive for the children. Prayer seemed to be the key for many caregivers:

\author{
"On my worst days...it's God. I have to \\ pray...its God" \\ "I have my faith. Believing in Jesus and God \\ help me to get through it." \\ "I start reading my Bible and I just pray \\ because some days I can be really down".
}

Only two caregivers used a formal support system, one $v i a$ an in-person support group.

There were parent support networks that I used to go to but I haven't gone for awhile. I've been think about going back to that just so I could talk to other people you know....raising a kid that's got a dad in prison, I don't know, but there's a lot of people in that situation.

The other had access to a computer and located an internet support group.

I joined a support group on the internet for women who have sons, husbands, boyfriends, anything, incarcerated and to hear the other stories that you're not, it's not just you.

Most of the caregivers who wanted a support group or other opportunities to network were unsuccessful, often not knowing where to begin in their quest. In particular, they wanted parenting ideas from others who shared their situation.

I want to be in a support group. I want to be in some type of group with adults that are in the same predicament as me. Maybe I need to get other feedback from other parents that's going through the same problems as me, having like a family, you know, a parent in prison that, you know, what are they doing to make it? And I guess I don't have no one to talk to about that.

Families also could provide meaningful support. In particular, caregivers spoke of close relationships with their own mothers,

My mom...she'll just tell me you can't quit, and she'll usually come over here to do something, like clean my bathroom...sometimes she'll take [the child]...for awhile, keeps him overnight so I can go do something with my girlfriends. Those are the most important ways she helps.

While several of the caregivers wished for a way to connect with others, most were not aware of such opportunities and did not have the spare time, resources, access, or awareness of venues to locate this kind of support. Even among those who found support in family, faith, or support groups, some indicated that while these supports helped them face each day, by and large they still felt a need for more powerful and consistent support that extended beyond crisis-based help.

\section{DISCUSSION}

In this study, caregivers of children of incarcerated parents struggled with some of the same issues that the children confront, but with the additional pressure of making decisions on their behalf. While most of the themes that surfaced here have been previously found in studies of children, they have seldom been presented from the caregiver's perspective. Much of what we know about the caregiver experience is focused on the burden that comes with raising a child as a grandparent or the added financial strain if the incarcerated parent had contributed to the household income.

Caregivers also suffer from the social and emotional impact of raising a child with an incarcerated parent. Just as with the children, the caregivers in this study endured associative social stigma from police, family, and friends, and found only limited sources of formal and informal support. Stigma has been discussed in one capacity or another in regard to children in past research, but not in regard to caregivers. This is important to recognize because when caregivers feel they cannot freely share their situation with others, it also limits their ability to find others in their situation and learn coping and parenting strategies specific to raising a child with an incarcerated parent.

Many priors studies as well as service providers who work with these families are quick to point out the barriers to bringing children to visits, given a child-unfriendly system $[4,18]$. The caregivers in this study who experienced visits shared similar concerns. This continues to be a problem that is not well-addressed in the penal system.

The caregivers were committed to the children but did not have adequate resources or information about how best to support the children. In particular, they struggled to facilitate a healthy child-parent relationship in keeping with developmental changes over the course of the prison term. Caring for a child who has a parent in prison raises some challenges that are unique to this population.

The impact of witnessing the arrest is something that has been noted occasionally in studies on children of incarcerated parents [12]. The traumatic effect this can have on children is not difficult to imagine. Caregivers are also affected by witnessing the arrest, and in ways that can trickle down to the children. When the child does not witness an arrest, caregivers have the time to consider how to reveal to the child that their parent was arrested, in developmentally appropriate ways. When the child witnesses the arrest, that option is eliminated. Moreover, caregivers themselves can be traumatized by an arrest, especially when it occurs by surprise in their own home.

The issue of caregiver gatekeeping is not well-examined to date. There is some evidence that incarcerated fathers feel frustration that caregivers who are also the mothers control the access to the children [15, 29]. While it is fact that caregivers do control contact between the incarcerated parent and the child, we found in this study that to caregivers it often felt like more of a duty and burden. The caregivers in our study revealed that they had little choice but to orchestrate the parent-child relationship because it could not unfold naturally with the parent in prison. At the same time, caregivers were often at a loss as to how to meet the 
children's needs within a judicial process and penal system that is not oriented toward families or children. They were continually confronted with difficult decisions, such as how to explain incarceration to the child, whether or not they should encourage parent-child communication, whether to expose the child to a prison setting, and how to help the child cope with the trauma of witnessing their parent's arrest.

\section{Opportunities for Change}

There are numerous venues to effect positive change for this population. A process integrated into court proceedings and prison systems that brings attention to the presence and needs of the families is essential. A pre-sentencing family assessment of the child and caregiver needs and potential family impact that results in a family plan could go a long way toward alleviating caregiving strains. Such a family plan might consider parental rights, facility distance from minor children, number and ages of children, and other visitation needs. To the degree that there is some flexibility in sentencing decisions, the plan could make formal recommendations to the court that might lessen the impact on caregivers and the children.

There is currently some effort underway toward this end. A partnership across fourteen states of universities, community agencies, and advocacy groups has been working in recent years toward legislative change at the national level. Their goal is to implement a bill of rights [30] that presents several policy and practice recommendations including: developing arrest protocols that take into account children's and caregiver's needs, encourage family-friendly visiting policies, and develop training for police officers, schools, and correctional facilities to be sensitive to children's needs.

Perhaps the most pervasive concern among the caregivers was isolation from others in their position and lack of support. Negotiating the relationship between the child and incarcerated parent is complicated and changes with the child's developmental needs. Caregivers need both concrete information to guide them in their role as gate-keeping, and also a way to connect to others in their situation who understand the nuances of it and can offer real-life examples of how they managed. Currently, there is not an adequate avenue that leads caregivers to each other. A low-cost effort for practitioners who work with these families is to offer a meeting space for a caregiver support group. Another way to bring families together while also assisting with prison visits is bus transport for visits. Girl Scouts Behind Bars found that a group transportation service brought families together who might not otherwise meet and that during the commute, the caregivers networked while the children observed that others too had a parent in prison [31].

Finally, creating family-friendly visiting spaces is a realistic goal. Naturally the prison's first priority is safety and all rules are viewed through that lens. However, a person knowledgeable about child development assigned on staff or on an advising board for visits may be able to provide a family-oriented perspective to the visiting rules. There is also some evidence that women's prisons are making changes to better accommodate children, though men's prisons, which comprise the vast majority of prisons, continue to lag behind. The women's visiting model can be used as a model for other facilities. Minnesota has a parenting program in its women's facility where inmates can earn admission to that offers a homelike setting, permits longer daytime and even some overnight visits, and structures the parent-child time with child-oriented activities [32]. It may be that that larger hurdle is recognizing that father-child relationships are important to nurture.

As children of incarcerated parents gain increasing national attention, it is imperative to view the children's needs in the context of the family in which they reside. The better we meet the needs of the caregivers by providing information, opportunities for networking, and other support immediately following the arrest and continuing through the duration of the incarceration, the more effective we will be at alleviating the impact of social stigma and better equipped the caregivers will be to support the children. Attending to the challenges, assets, and needs of the caregivers will serve to enhance and expedite efforts to improve the lives of these children.

\section{ACKNOWLEDGEMENT}

To Sarah Krueger for her contributions to the original data collection and analysis.

\section{CONFLICT OF INTEREST}

None declared.

\section{REFERENCES}

[1] Glaze LE, Maruschak LM. Parents in prison and their minor children. Washington, DC: U.S. Department of Justice 2008.

[2] Travis J, Waul M. Prisoners once removed: the impact of incarceration and reentry on children, families and communities. Washington, DC: The Urban Institute Press 2003.

[3] Bouchet SM. Children and Families with incarcerated parents: exploring development in the field and opportunities for Growth. Baltimore, MD: Annie E. Casey Foundation; 2008.

[4] Hairston CF. Focus on children with incarcerated parents: An overview of the research literature. Baltimore, MD: Annie E. Casey Foundation 2007.

[5] Dworsky A. Foster care placement among children with incarcerated mothers. Presented at Thursday's Child Forum. Washington, DC: The Urban Institute 2008.

[6] Davies E, Brazzell D, LaVigne NG, Shollenberger T. Understanding the experiences and needs of children of incarcerated parents: views from mentors. Washington, DC: Urban Institute Justice Policy Center 2008

[7] Hanlon TE, Carswell SB, Rose M. Research on the caretaking of children of incarcerated parents: Findings and their service delivery implications. Child Youth Serv Rev 2007; 29: 348-62.

[8] Gabel K, Johnston D. Children of incarcerated parents. New York: Lexington Books 1995.

[9] Johnson E, Waldfogel J. Parental incarceration: recent trends and implications for child welfare. Soc Serv Rev 2002; 76(3): 460-79.

[10] Phillips S, Bloom B. In whose best interest? the impact of changing public policy on relatives caring for children with incarcerated parents. Child Welfare 1998; 77(5): 531-42.

[11] Adalist-Estrin A. Why Maintain relationships. children of prisoners library: Facts Issues. CPL 199; 5102.

[12] Bernstein, N. All Alone in the World: Children of the incarcerated. New York: The New Press 2005.

[13] Mumola, CJ. Incarcerated parents and their children. Bureau of Justice Statics Special Report Washington, DC: U.S. Department of Justice 2000.

[14] Hairston CF, Rollin J, Jo H. Family connections during imprisonment and prisoners' community reentry. Research brief: children, families, and the criminal justice system. Chicago: University of Illinois 2004. 
[15] Roy, KM, Dyson OI. Gatekeeping in context: Babymama drama and the involvement of incarcerated fathers. Fathering 2005; 3(3): 289-310.

[16] Nesmith A, Ruhland E. Children of incarcerated parents: challenges and resiliency, in their own words. Child Youth Serv Rev 2008; 30: 1119-30.

[17] Krisberg BA, Temin CE. The plight of children whose parents are behind bars. Oakland, CA: National Council on Crime and Delinquency 2001.

[18] Slavin P. Children with parents behind bars. Child Voice 2000; 9(5): 4-37.

[19] LaVigne NG, Davies E, Brazzell D. Broken bonds: understanding and addressing the needs of children with incarcerated parents. Washington, DC: Urban Institute 2008.

[20] Quinn DM, Chaudoir SR. Living with a concealable stigmatized identity: The impact of anticipated stigma, centrality, salience, and cultural stigma on psychological distress and health. J Pers Soc Psychol 2009; 97(4): 634-51.

[21] Corriga PW, Miller FE. Shame, blame, and contamination: A review of the impact of mental illness stigma on family members. $\mathbf{J}$ Ment Health 2004; 13: 537-48.

[22] Wight RG, Aneshensel CS, Murphy DA, Miller-Martinez D, Beals KP. Perceived HIV stigma in AIDS caregiving dyads. Soc Sci Med 2006; 62: 444-56.
[23] Hagen J, Dinovitzer R. Collateral consequences of imprisonment for children, communities, and prisoners. Crime Just 1999; 26: 12162 .

[24] Link BG, Phelan JC. Conceptualizing stigma. Ann Rev Sociol 2001; 27: 363-85.

[25] Mickelson KD. Perceived stigma, social support, and depression Pers Soc Psychol Bull 2001; 27: 1046-56.

[26] Minnesota Department of Corrections. Statistics about the Department of Corrections. 2004; http://www.corr.state.mn.us/abo utdoc/stats/

[27] Tesch R. Qualitative Research: analysis types and software tools. London: Psychology Press; 1990.

[28] Minnesota Department of Corrections. Statewide Visiting Room Rules. St. Paul, MN: MN Department of Corrections; 2009.

[29] Mendez GA. Incarcerated African American men and their children: A case study. Ann Am Acad Politic Soc Sci 2000; 568: 86-101.

[30] San Francisco Partnership for Incarcerated Parents. Children of Incarcerated Parents Bill of Rights; 2003.

[31] Block, KJ, Potthast, MJ. Girl Scouts Beyond Bars: Facilitating parent-child contact in correctional settings. Child Welfare 1998 77(5): 561-78.

[32] Minnesota Department of Corrections. Parenting Programs: Minnesota Correctional Facility-Shakopee. St. Paul, MN: MN Department of Corrections 2010.

(C) Nesmith and Ruhland; Licensee Bentham Open.

This is an open access article licensed under the terms of the Creative Commons Attribution Non-Commercial License (http: //creativecommons.org/licenses/by$\mathrm{nc} / 3.0 /$ ) which permits unrestricted, non-commercial use, distribution and reproduction in any medium, provided the work is properly cited. 